\title{
Iron Metabolism in the Laying Hen
}

\author{
By W. N. M. RAMSAY AND E. A. CAMPBELL \\ Departments of Biochemistry and Veterinary Physiology, University of Edinburgh
}

(Received 2 April 1954)

The laying hen excretes relatively large quantities of iron in the eggs. In our experience, a weekly output of $6 \mathrm{mg}$. $\mathrm{Fe}$ is not uncommon, and a good layer may lose 150-200 mg. in a year. This loss, which is not suffered by the non-laying bird, is so great that interesting changes in the processes of iron metabolism must precede or accompany the onset of laying. This paper presents the results of some investigations in this field.

Widdowson \& McCance (1948) showed that the domestic fowl resembles many mammals in that the liver of the female contains more iron than that of the male. The effect, however, is manifest some weeks before the onset of laying, and the quantity of iron involved is small compared with that in the eggs. It is well known that the blood of cocks contains more haemoglobin than that of hens, while Cook \& Harmon (1933), Maughan (1935) and Harmon (1936) all reported that blood haemoglobin was lower in the laying than in the non-laying hen. Cook \& Harmon (1933) and Harmon (1936) went further, and claimed an inverse relation between blood haemoglobin and egg production during the laying season. Their results, however, were quoted in terms of mean haemoglobin and total egg production for an entire flock, and might therefore be explained by changes in the numbers of laying and non-laying birds. All these findings stand in opposition to those of Dukes \& Schwarte (1931) and Winter (1936), who found no relation between egg production and blood haemoglobin. A re-investigation seemed necessary, and since some of the findings suggested that the demand for iron for the eggs might create an iron deficiency in the laying bird, serial determinations of total blood iron and plasma iron were undertaken in a small flock of birds throughout a laying season. All eggs were also analysed for iron.

In a separate experiment pullets were killed at intervals over the period during which laying commenced, and the livers, spleens and kidneys analysed for total and non-haem iron.

\section{METHODS}

General. All birds were maintained at the Poultry Research Centre, Edinburgh. Brown Leghorns were used, and most were fed on the stock breeding diet. This contains a supplement of $\mathrm{FeSO}_{4}$, and provides 5-6 mg. Fe per day. A few birds were fed for 2 months on the same diet without the iron supplement, but although this lowered the dietary intake of iron by some $20 \%$, these birds behaved in all respects similarly to the others. No attempt has therefore been made to present the results separately.

The birds were trapnested to permit the collection of eggs from individual birds.

Blood specimens were drawn as required (usually 4-5 ml. every 3 weeks) from the alar vein into heparinized ('Liquemin' Roche) syringes. It was assumed that the loss of 1.2-1.5 mg. Fe in each blood specimen would be insignificant in comparison with the loss of $12-20 \mathrm{mg}$. in the eggs during the 3-week period.

Total blood iron was determined on $0.05 \mathrm{ml}$. specimens by the $\mathrm{H}_{2} \mathrm{O}_{2}$-sulphite-dipyridyl technique of Ramsay (1952), except that the final heating was continued for $15 \mathrm{~min}$. to ensure full colour development, and the volume adjustment was made with water instead of ethanol to a total of $7.5 \mathrm{ml}$. Haemoglobin concentrations were calculated from the results by assuming that fowl haemoglobin resembles many mammalian haemoglobins in containing about $0.34 \% \mathrm{Fe}$.

Plasma iron was determined by the $\mathrm{NH}_{2} \mathrm{OH}$-dipyridyl technique of Ramsay (1953). As this method gives high results on perceptibly haemolysed specimens, it is important to note that none of the samples analysed showed any spectroscopically detectable trace of haemolysis. The technique was checked by making duplicate analyses on pairs of specimens taken almost simultaneously with different apparatus from the two wings of each bird. The difference between the two wings never exceeded $10 \%$, and was usually much less.

Egg iron was determined by the $\mathrm{NH}_{2} \mathrm{OH}$-dipyridyl technique of Ramsay (1951). In the early stages of the work, and at intervals later, the eggs were analysed individually, but it was found that little information was lost and much time saved if the eggs laid by each bird were pooled weekly before analysis.

Liver, spleen and kidney iron. Suspensions which could be pipetted with wide-mouthed pipettes were prepared by cutting up the whole organ in 5 or 10 vol. of water and treatment of the mixture in a macerator (Townson \& Mercer) in which there was no risk of contamination with traces of metal from the bearings. A final treatment was given in the glass homogenizer of Potter \& Elvehjem (1936). The spleens were so small that it was possible to omit the preliminary maceration.

Total iron was determined on $0.5-1.0 \mathrm{ml}$. portions of the suspensions by the $\mathrm{H}_{2} \mathrm{O}_{2}$-sulphite-dipyridyl technique (Ramsay, 1952), but it was found necessary to extend the heating period to $60 \mathrm{~min}$. when the tissues of adult fowls were analysed. This procedure gave results similar to those obtained by destruction of the tissue with $\mathrm{H}_{2} \mathrm{SO}_{4}, \mathrm{HClO}_{4}$ and $\mathrm{HNO}_{3}$ before neutralization, reduction and treatment with dipyridyl. The difference between the two techniques was never more than $5 \%$. 
The determination of non-haem iron in these tissues could not be successfully carried out by heating with dipyridyl in the presence of sulphite or $\mathrm{NH}_{2} \mathrm{OH}$. Numerous other reducing agents were tested, but always added haemoglobin gave a high result, although added haemin (perhaps because of its insolubility in the acetate buffers used) did not. The failure of sulphite to prevent haemoglobin interference in these tissue analyses is interesting in view of its successful use in the determination of plasma iron in haemolysed specimens (Ramsay, 1954). It was found, however, that if both tissue suspension and reagents were fully saturated with $\mathrm{CO}$ before mixing and heating, the interfering effect of added haemoglobin was abolished, but only if sulphite was used as reducing agent. The treatment with $\mathrm{CO}$ was suggested by the experiments of Legge \& Lemberg (1941), who showed that the liberation of 'easily split iron' from blood or haemoglobin solutions was greatly decreased by preliminary exposure to CO. It was found advantageous to work at a fairly low $\mathrm{pH}$, and the procedure finally adopted was as follows. Tissue suspension (0.5-1.0 ml.), after saturation with CO (prepared by dropping conc. formic acid into conc. $\mathrm{H}_{2} \mathrm{SO}_{4}$ ) was pipetted into a tube graduated at $7.5 \mathrm{ml}$., and treated with $1 \mathrm{ml} .0 .5 \mathrm{M}-\mathrm{Na}_{2} \mathrm{SO}_{3}$, and $5 \mathrm{ml}$. $\mathrm{M}$ acetate buffer, $\mathrm{pH} 4 \cdot 25$, containing $2: 2^{\prime}$-dipyridyl $(0 \cdot 2 \%)$. The composition of the reagents is not critical. Both reagents were saturated with CO just before use. The tube was heated in a boiling water bath for 30 min., cooled, and the volume made up to $\mathbf{7 . 5} \mathrm{ml}$. After filtration through an iron-free paper the optical density was measured against a complete reagent 'blank' in a Unicam S.P. 350 Spectrophotometer at $520 \mathrm{~m} \mu$. If the $\mathrm{CO}$ treatment was adequate, the precipitated protein remained pink throughout the heating period. A change of colour to brown at any stage betrayed the necessity for a repetition of the analysis, not only because of the possibility of interference by haem pigments, but also because the rate of formation of the ferrous dipyridyl complex was much slower when the $\mathrm{CO}$ treatment was incomplete. Table 1 shows that inorganic iron added to liver suspensions was satisfactorily recovered, while haemoglobin iron did not affect the results significantly. Moreover, the livers analysed appeared to contain 85-101\% of the total iron in non-haem compounds. For these reasons it was felt that the method probably gave a good estimate of non-haem iron, and that no great error would be risked in applying it to spleen and kidney, where the proportion of non-haem iron was much less (usually $50-60 \%)$.

Table 1. Recovery of inorganic and non-recovery of haemoglobin $\mathrm{Fe}$ added to liver suspension

$\begin{array}{ccc}\begin{array}{c}\text { Non-haem Fe } \\ \text { originally present } \\ (\mu \mathrm{g} . / \text { tube })\end{array} & \begin{array}{c}\text { Fe added } \\ (\mu \mathrm{gg})\end{array} & \begin{array}{c}\text { Non-haem } \\ \text { Fe found } \\ (\mu \mathrm{g} . / \text { tube })\end{array} \\ \begin{array}{c}\text { Inorganic Fe added } \\ 12 \cdot 5\end{array} & 3 \cdot 4 & \\ 12 \cdot 5 & 3 \cdot 9 & 15 \cdot 8 \\ 12 \cdot 5 & 5 \cdot 1 & 16 \cdot 4 \\ 6 \cdot 5 & 5 \cdot 6 & 17 \cdot 3 \\ 9 \cdot 2 & 4 \cdot 8 & 12 \cdot 0 \\ & & 14 \cdot 3 \\ 20.2 & \text { Haemoglobin Fe added } \\ 23 \cdot 6 & 10 \cdot 3 & 19 \cdot 6 \\ & 10 \cdot 3 & 23 \cdot 9\end{array}$

\section{EXPERIMENTAL AND RESULTS}

In a first experiment sixteen birds (one of which laid poorly, became repeatedly crop-bound, and was ultimately discarded) were observed from the commencement of the laying season at the end of December until the following autumn. All eggs were analysed and. at intervals of 3 weeks blood specimens were used for the determination of total iron and plasma iron. Four of the birds were unfortunately not bled until just after they had commenced to lay, and it was only possible to follow eight of the birds until they ceased to lay in the autumn. This was because laying commenced, in different birds, between the end of December and the end of February, and ceased between midSeptember and some time after the end of October, when it was necessary to terminate the experiment. The general trend of the results, however, was so uniform, and has been so completely borne out by later experiments, that these omissions would seem to have been comparatively harmless.

Plasma iron. Until about 10 days before a hen began to lay, its plasma iron concentration lay between 100 and $250 \mu \mathrm{g} . / 100 \mathrm{ml}$., a range similar to that found in man and many other mammals. Shortly before laying commenced it rose to 500 $900 \mu \mathrm{g} . / 100 \mathrm{ml}$., and fluctuated (usually narrowly) within these high limits as long as eggs were regularly produced. Cessation of egg production

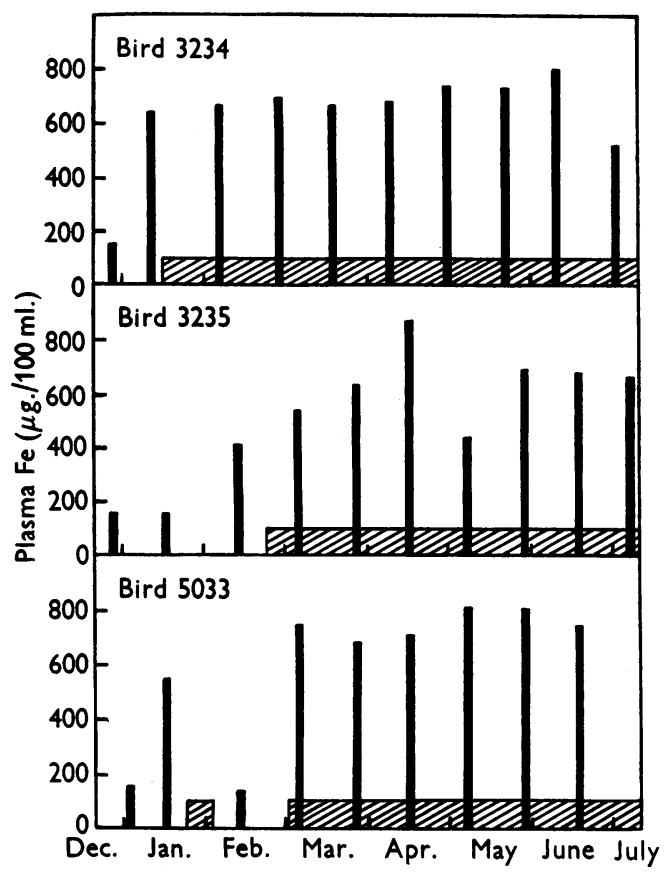

Fig. 1. Plasma iron in laying hens. The hatched areas indicate the periods during which each hen was laying. 
was accompanied by a return to the original low level. No exceptional behaviour was detected. Fig. 1 shows three typical examples of the prelaying rise and the maintenance of the high level during regular laying. Bird no. 5033 is interesting because a temporary cessation of egg production was matched by a fall in plasma iron. This diagram does not illustrate the post-laying decrease, but the eight specimens taken after the cessation of laying gave results of $117-191 \mu \mathrm{g}$. $\mathrm{Fe} / 100 \mathrm{ml}$. with a mean of $137 \mu \mathrm{g} . / 100 \mathrm{ml}$. Some figures from a later experiment, which show very clearly the relation of plasma iron concentration to the onset of laying, are given in Table 3.

Haemoglobin. Blood haemoglobin concentrations calculated from all the total iron determinations made before the middle of July are summarized in Table 2. The values were usually fairly constant during the laying period, and fluctuated by 5-10\% about a mean. In two birds only was there a definite tendency for haemoglobin to decline as the laying season progressed, but in 7 of 11 hens one or more pre-laying values was higher by 2-6 standard deviations than the mean of 8-10 values obtained during laying. Moreover, in two of the four in which no pre-laying decrease was noted the pre-laying specimen was taken only a day or two before laying commenced, and the plasma iron had already risen to the laying level. It seems very likely that in those cases the haemoglobin had already fallen to the laying level.

Egg iron. Although more than 2500 eggs were analysed, the results were of little intrinsic interest.
The average iron content of all the eggs laid between March and June, when all the birds were laying regularly, was $0.88 \mathrm{mg}$./egg (range 0.76-1.07 mg.), rather less than other figures reported from this laboratory (Ramsay, 1950, 1951). The birds in all cases have come from the same Brown Leghorn strain, but the difference may result from the fact that the birds used in the present investigation were pullets, and laid eggs weighing only about $40 \mathrm{~g}$.

Liver, spleen and kidney iron. As the investigations described above had shown changes in both plasma iron and blood haemoglobin to be associated with the onset of laying, it seemed of interest to find out whether there were also changes in the iron stores at this physiologically critical period. A series of pullets was therefore killed shortly before or shortly after they commenced to lay. Blood specimens were taken within a day or so of death, and the livers, kidneys and spleens removed for the determination of non-haem and total iron. An attempt was made to relate the results to the stage of ovarian development, which was described for present purposes in terms of the number and size of the yolks present. The results are summarized in Table 3.

\section{DISCUSSION}

Haemoglobin. The haemoglobin determinations made in this work are in fairly good agreement with the finding of Cook \& Harmon (1933), Maughan (1935) and Harmon (1936) that the concentration of haemoglobin is lower in the blood of laying than of

\section{Table 2. Blood haemoglobin in laying hens}

Double and treble figures in the last column refer to two and three analyses on different occasions. Figures in parenthesis show the number of occasions on which determinations were made.

\begin{tabular}{|c|c|c|c|}
\hline \multirow[b]{3}{*}{ Bird no. } & \multicolumn{3}{|c|}{ Haemoglobin (g. $/ 100 \mathrm{ml}$.) } \\
\hline & \multicolumn{2}{|c|}{ While laying } & \multirow[b]{2}{*}{ Before laying } \\
\hline & Mean & S.D. & \\
\hline 3221 & $9 \cdot 1 \quad(9)$ & 0.45 & - \\
\hline 3234 & $8 \cdot 6(10)$ & $0 \cdot 46$ & $10 \cdot 3$ \\
\hline 3235* & $8.9 \quad(8)$ & $0 \cdot 60$ & $11 \cdot 5,10 \cdot 7,12 \cdot 0$ \\
\hline $3236^{*}$ & $8.8(10)$ & 0.60 & - \\
\hline 3239 & $8 \cdot 6 \quad(8)$ & $0 \cdot 10$ & $8 \cdot 4,8 \cdot 4$ \\
\hline 5033 & $8 \cdot 0 \quad(6)$ & 0.90 & $9 \cdot 1,9 \cdot 9,9 \cdot 9$ \\
\hline 5080 & $8 \cdot 7(10)$ & $0 \cdot 61$ & - \\
\hline $\mathbf{5 2 3 7}$ & $8.4 \quad(8)$ & 0.42 & $8 \cdot 2$ \\
\hline 5272 & $8.5(10)$ & $0 \cdot 35$ & - \\
\hline 5297 & $8.4(10)$ & $0 \cdot 31$ & $8.5 \dagger$ \\
\hline 5313 & $8 \cdot 3 \quad(8)$ & 0.32 & $10 \cdot 5,10 \cdot 3$ \\
\hline 5314 & $8.9 \quad(8)$ & 0.57 & $9 \cdot 3 \dagger$ \\
\hline 5322 & $8 \cdot 2(10)$ & 0.42 & $9 \cdot 1 \dagger$ \\
\hline 5325 & $7.9 \quad(9)$ & 0.32 & $8 \cdot 2,10 \cdot 3$ \\
\hline 5947 & $8 \cdot 6 \quad(9)$ & 0.35 & $10 \cdot 2,10 \cdot 3$ \\
\hline
\end{tabular}

* In these birds blood haemoglobin declined steadily from $9 \cdot 7$ and $9.9 \mathrm{~g} . / 100 \mathrm{ml}$. respectively to $8.0 \mathrm{~g} . / 100 \mathrm{ml}$. in 4 and 6 months after the onset of laying.

$\dagger$ These observations were made only very shortly before the onset of laying, and in each case the plasma Fe had already risen to the laying level. 


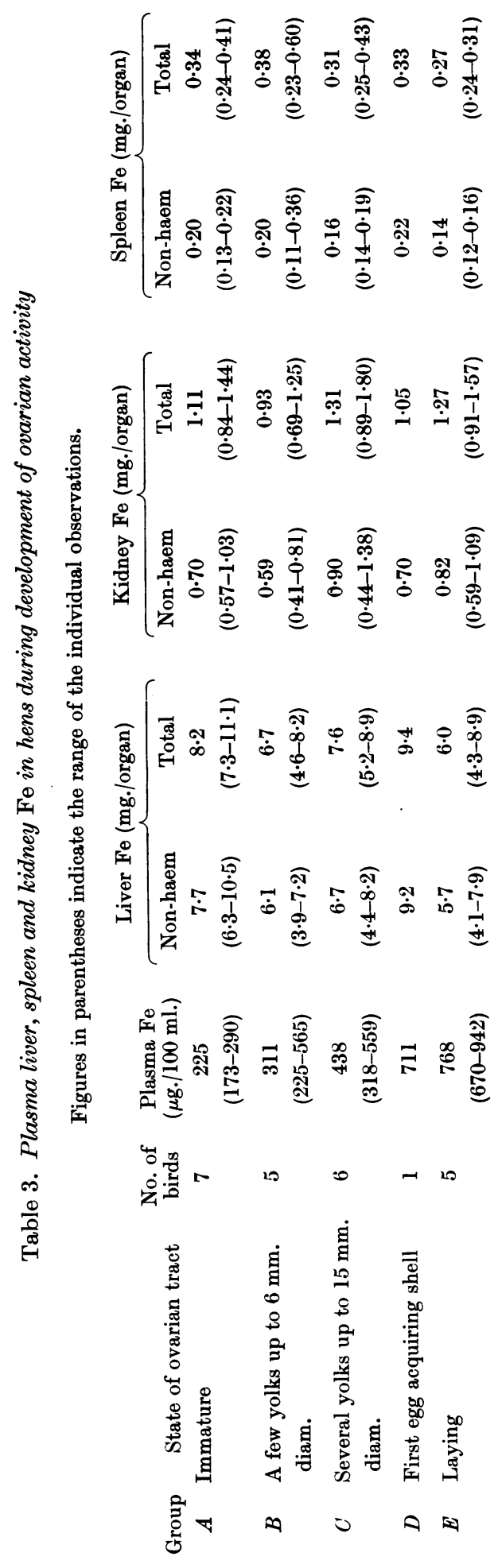

non-laying hens. The effect was smaller than that described by the earlier workers, the difference apparently being attributable to the fact that in their laying hens the blood haemoglobin fell to 6-7 g./100 ml., whereas our values were usually 8-9 g./100 ml., and rarely less than $7 \cdot 5 \mathrm{~g} . / 100 \mathrm{ml}$. This, and the possibility disclosed in our experiments that some birds may not show the effect at all, may account for the contrary findings of Dukes \& Schwarte (1931) and Winter (1936).

It is an attractive hypothesis that this decrease in haemoglobin is, perhaps through some endocrine intervention, dependent on the demand for iron for the eggs. The small decrease in circulating haemoglobin observed would, however, only provide 3-5 mg. iron for the eggs, and it is at least equally probable that the change in haemoglobin concentration reflects a change in plasma volume. We have made attempts to investigate this point by the determination of plasma volume with Evans Blue, but have encountered difficulties which seriously invalidate the results. The dye, for example, is very rapidly transmitted to the eggs.

The fact that the laying level of haemoglobin is maintained more or less constant in the face of continued excretion of iron in the eggs argues strongly against there being any degree of iron deficiency whatever.

Egg iron and plasma iron. When a comparison is made of egg iron with plasma iron, by plotting against one another the mean values of the two over the 4-month period March-June, when laying was most regular, the interesting fact emerges that there is a very definite relation between the two. This is shown graphically in Fig. 2. The correlation co-

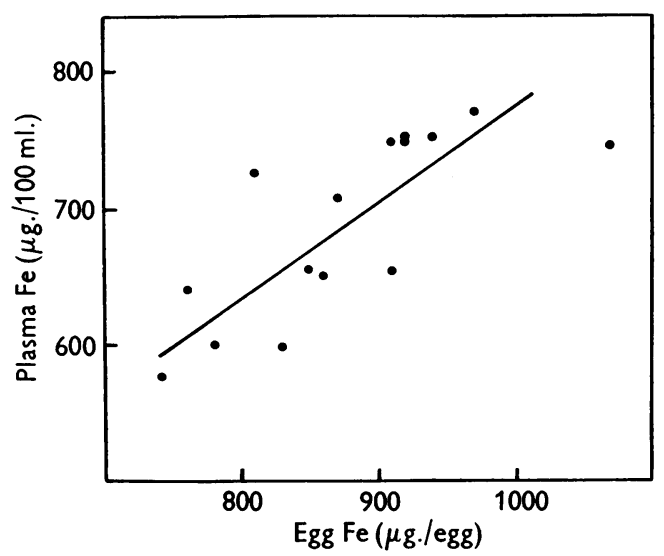

Fig. 2. The relation between egg iron and plasma iron. The points were obtained by plotting the mean egg iron over 4 months against the mean plasma iron (determined every 3 weeks) during the same period. Fifteen birds were used. The straight line was calculated from the correlation coefficient $r=0.717(P<0.001)$. 
efficient in our experiment was $0.717(P<0.001)$. This finding is consistent with the view that the egg iron is directly derived from the plasma iron. Other statistical comparisons suggested that there was no relation between plasma iron and number of eggs or the total amount of iron excreted in the eggs, or between blood haemoglobin and mean egg iron, total egg iron, or number of eggs. The last of these comparisons supports the view that the relation found by Cook \& Harmon (1933) and Harmon (1936) between blood haemoglobin and number of eggs, might have resulted from an unsound method of calculation. Increases in many blood constituents have been associated with egg production (most of the available information was tabulated and discussed by Romanoff \& Romanoff, 1949), but it is believed that this is the first occasion on which a quantitative relation has been established between the plasma concentration of a substance and the amount present in the eggs.

Liver, spleen and kidney iron. Table 3 shows that the liver contains 8-10 times as much non-haem iron as the kidney, and that again 3-5 times as much as the spleen, which in birds is a small organ. In these hens the spleen weighed only 1-2 g. The liver thus contains the great bulk of the small store of iron carried by the hen. The livers of the nonlaying pullets contained an average of $7 \cdot 7 \mathrm{mg}$. nonhaem iron while those of the laying ones contained $5.7 \mathrm{mg}$. The numbers of birds were too small for this difference to be considered significant, and in any case it is much less than the amount of iron (5-10 mg.) transferred by the laying birds to the eggs. A small number of analyses made at longer intervals after the onset of laying suggested that the non-haem iron in the liver may perhaps decrease slowly during the laying season.

It is interesting to note that the development of ovarian activity is accompanied by a large increase (from 25-35 g. to 45-60 g.) in the weight of the liver. The organ becomes pale and apparently fatty, although we have not checked this point by analysis.

Iron absorption. Even if it be assumed that the pre-laying decreases in blood haemoglobin and liver non-haem iron are real, and have the effect of providing iron for the eggs, these changes can provide iron for at the most some 6-8 eggs. There can be no doubt, therefore, that the demand for iron must be met very largely by an increase in the efficiency of iron absorption. It may be calculated from iron intake and egg iron that the laying birds in our experiments must have absorbed some $15-20 \%$ of the dietary iron, in spite of the fact that the diet was rich in cereals, and hence in phytate, which might have been expected (Widdowson \& McCance, 1942;
McCance, Edgecombe \& Widdowson, 1943) to exert an adverse influence on iron absorption.

\section{SUMMARY}

1. Determinations of egg and plasma iron over a whole season in fifteen birds showed a great elevation of plasma iron just before laying commenced. The high level persisted during the period of regular laying, and there was a high correlation $(r=0.717, P<0.001)$ between mean plasma iron and mean egg iron.

2. Total blood iron determinations over the same period suggested that in many hens the onset of laying is preceded by a fall in blood haemoglobin. The lower level persists during the period of regular laying.

3. Determinations of total and non-haem iron in liver, spleen and kidney over the short period during which hens were coming into lay suggested that there may perhaps be a slight decrease in non-haem iron in the liver at this time, but that the quantity involved is small compared to that utilized for the eggs in the same period.

4. It is concluded that the demand for iron for the eggs must be met by an increase in the efficiency of iron absorption.

The authors acknowledge with pleasure the invaluable co-operation of Dr A. W. Greenwood and the staff of the Poultry Research Centre; the efficient technical assistance of Messrs R. Hope and G. R. Wilson; and a grant from the Agricultural Research Council to one of us (W.R.) from which much of the expense of the work was met.

\section{REFERENCES}

Cook, S. F. \& Harmon, I. W. (1933). Amer. J. Physiol. 105, 407.

Dukes, H. H. \& Schwarte, L. H. (1931). Amer. J. Physiol. 96, 89.

Harmon, H. H. (1936). Poult. Sci. 15, 53.

Legge, J. W. \& Lemberg, R. (1941). Biochem. J. 35, 353.

McCance, R. A., Edgecombe, C. N. \& Widdowson, E. M. (1943). Lancet, $2,126$.

Maughan, G. H. (1935). Amer. J. Physiol. 113, 96.

Potter, V. R. \& Elvehjem, C. A. (1936). J. biol. Chem. 114, 495.

Ramsay, W. N. M. (1950). Biochem. J. 46, 168.

Ramsay, W. N. M. (1951). Biochem. J. 49, 494.

Ramsay, W. N. M. (1952). Biochem. J. 51, 289.

Ramsay, W. N. M. (1953). Biochem. J. 53, 227.

Ramsay, W. N. M. (1954). Biochem. J. 57, xvii.

Romanoff, A. L. \& Romanoff, A. J. (1949). The Avian Egg. London: Chapman and Hall.

Widdowson, E. M. \& McCance, R. A. (1942). Lancet, 1, 588. Widdowson, E. M. \& McCance, R. A. (1948). Biochem. J. $42,577$.

Winter, A. R. (1936). Poult. Sci. 15, 252. 